\title{
Antimicrobial prophylaxis in colorectal surgery: focus on ertapenem
}

This article was published in the following Dove Press journal:

Therapeutics and Clinical Risk Management

13 October 2009

Number of times this article has been viewed

\section{Fausto de Lalla}

Libero Docente of Infectious Diseases, University of Milano, Milano, Italy
Correspondence: Fausto de Lalla viale Milano 27,36100 Vicenza, Italy $\mathrm{Tel}+39337487470$

Email faustodelalla@alice.it

\begin{abstract}
Despite improvement in infection control measures and surgical practice, surgical site infections (SSIs) remain a major cause of morbidity and mortality. In colorectal surgery, perioperative administration of a suitable antimicrobial regimen that covers both anaerobic and aerobic bacteria is universally accepted. In a prospective, double-blind, randomized study ertapenem was recently found to be more effective than cefotetan, a parenteral cephalosporin so broadly used as to be considered as gold standard in the prevention of SSIs following colorectal surgery. In this adequate and well controlled study, the superiority of ertapenem over cefotetan was clearly demonstrated from the clinical and bacteriological points of view. However, data that directly compares ertapenem with other antimicrobial regimen effective in preventing SSIs following colorectal surgery are lacking; furthermore, the possible risk of promotion of carbapenem resistance associated with widespread use of ertapenem prophylaxis as well as the ertapenem effects on the intestinal gut flora are of concern. Further comparative studies of ertapenem versus other widely used prophylactic regimens for colorectal surgery in patients submitted to mechanical bowel preparation versus no preparation as well as further research on adverse events of antibiotic prophylaxis, including emergence of resistance and Clostridium difficile infection, seem warranted.
\end{abstract}

Keywords: colorectal surgery, surgical prophylaxis, ertapenem

\section{Introduction}

Surgical site infections (SSIs) are defined as infections occurring within 30 days - or within one year in the case of implantation of a foreign body - after a surgical operation, and affecting either the incision, superficially or deeply, or organs, or body spaces at the site of operation. ${ }^{1}$ Despite improvement in infection control measures and surgical practice, SSIs remain a major cause of morbidity and mortality and result in additional expenses to cover excessive hospitalization, treatment, and additional surgical procedures. The length of stay for patients who have a postoperative infection is 3-11 days and 9.8 days longer in studies from the US and Europe, respectively, ${ }^{2-7}$ than hospitalization for patients not undergoing postoperative complications. In the $1990 \mathrm{~s}$, the mean direct costs due to a postoperative infection have been estimated to be US $\$ 3,000,{ }^{8}$ adding $10 \%-20 \%$ to the cost of the total hospital bill. ${ }^{9}$ In a recent study of hospital costs attributable to surgical complications an increased cost of US\$1,309 per patient and infection was found. ${ }^{2}$ As for colorectal surgery, costs of US\$42,516 $\pm 39,972$ and of US\$10,999 $\pm 7,122$ for each infected versus uncomplicated operation, have recently been described. ${ }^{10}$ On average, US\$6,200/patient of home health expenses related to a wound care has also been found for wound infections following 
colorectal operations which are diagnosed and treated at home. ${ }^{11}$ Overall, it has been estimated that SSIs contribute to 3.7 million excess hospital days, and over US\$1.6 billion in hospital and patient costs. ${ }^{12,13}$ In Europe, available data suggest that the mean cost of prolonged hospitalization due to a postoperative infection is $€ 325$ per day. ${ }^{7}$ Deep SSIs involving organs or body spaces are associated with an even longer length of stay and increases in costs than superficial postoperative infections affecting only the incision. ${ }^{14}$

\section{Incidence of SSIs}

The incidence of SSIs varies widely between surgical procedures, hospitals and surgeons, and between patients. ${ }^{15}$ According to data from the Centers for Disease Control National Nosocomial Infections Surveillance (CDC-NNIS) system, SSIs account for $14 \%-16 \%$ of reported nosocomial infections among all hospitalized patients, and 38\% among surgical patients. ${ }^{1,16}$ In Europe, available data show that the incidence of these infections can be as high as $20 \%$, depending on the surgical procedure considered, the surveillance criteria used, and the study design. ${ }^{17}$ Due to high risk of bacterial contamination from the flora of the patient's large bowel during operation, colorectal surgery is associated with a particularly high risk of postoperative infection. SSI rates of up to $40 \%$ and of about $25 \%$ have been found in patients not receiving ${ }^{18}$ or receiving ${ }^{11}$ perioperative antibiotic prophylaxis, respectively. Indeed, the opening of the intestinal lumen always involves a relevant risk for bacterial contamination of the operative field and therefore for postoperative wound infection. In patients having surgical wound infection following operations on the large intestine, the risk of death is doubled, intensive care unit admission more likely, and the average hospital stay is increased by five days. ${ }^{8}$ Furthermore, the risk of hospital readmission is greatly increased. ${ }^{8}$

\section{Pathophysiology and microbiology of SSIs in colorectal surgery}

Although pathogens responsible for SSIs may originate from exogenous sources, either intraoperatively, such as from members of the surgical team, the surgical theater environment, and equipment, or postoperatively, such as from drains or surgical wound dressings, most surgical infections are acquired intraoperatively, and the responsible pathogens originate from the patient's endogenous flora. ${ }^{1}$ In large bowel surgery, which is the site associated with the greatest incidence of postoperative infections, the opening of the viscera can cause dissemination into the operative field of fecal microorganisms located into the colon and rectum. If the surgical procedures are carried out with skilled technique, and in the absence of pre-existing local infection, the colorectal operation with opening of colorectum is considered a clean-contaminated operation. ${ }^{19}$ On the contrary, if during operation a considerable fecal spillage occurs due to a break in surgical technique, colorectal surgery is considered a contaminated operation.

After microbial contamination of the operative field, the risk of a SSI depends on the dose and virulence of contaminating microorganisms and the level of resistance of patient. The relationship is the following:

Risk of SSI $=\frac{\text { Dose of bacterial contamination } \times \text { virulence }}{\text { Resistance of patient }}$

Clinically apparent infection results when bacterial contamination overcomes host defense mechanisms. The risk of postoperative infection is considered to be elevated when the level of contamination exceeds $10^{5}$ microorganisms per gram of tissue, ${ }^{20}$ although lower doses may be sufficient if foreign materials, such as suture, are present in the operative field. ${ }^{1,21}$ The virulence of the infecting microorganism depends on its ability to produce toxins and/or other factors which can increase the bacterial invasion and damage of tissues. Violation in sterile technique, preoperative shaving, prolonged preoperative hospitalization, and presence of a remote infection, have also been linked to an increased risk of postoperative infection. ${ }^{1,21,22}$ Other risk factors for postoperative infection related to the surgical procedure include quality of surgical care, type and duration of surgery, emergency procedure, blood transfusion, intraoperative hypothermia, and systemic hypoxemia. ${ }^{23-26}$ As for patient resistance, intrinsic patient characteristics strictly correlating with an increased risk of wound infection include advanced age (at least up to 65 years), ${ }^{27}$ an American Society of Anesthesiologists (ASA) score of III, ${ }^{21,28}$ obesity, ${ }^{11,29}$ pre-existing illness, ${ }^{22}$ and host defense deficiency.

SSIs following colorectal surgery are usually polymicrobial infections because of the very rich bacterial flora of the colorectal tract $\left(10^{6}-10^{8}\right.$ and $10^{9}-10^{11}$ microorganisms per $\mathrm{g}$ /fecium for aerobes and anaerobes, respectively).$^{30}$ Indeed, in the septic complications following surgical opening of distal intestinal tract, the most common finding is a mixed enteric flora of aerobes and anaerobes, with culture of up to 4-5 different species of aerobic and anaerobic microorganisms. The predominant isolates are Bacteroides fragilis and Escherichia coli; however other Gram-negative 
rods, Enterococcus spp, as well as other anaerobes including other members of the Bacteroides group, Fusobacterium spp, Peptococcus spp, and Peptostreptococcus spp can also be isolated..$^{30}$ Over the last 15 years, a rise in both Grampositive and Gram-negative resistant organisms in nosocomial infections has been described. In surgical patients, Gram-positive bacteria, and mainly methicillin-resistant staphylococci, are causing more and more serious infections than ever before. Indeed, the impact of these infections can be profound, ranging from prolonged hospital stay and increased morbidity and mortality. ${ }^{31,32}$ However, SSIs caused by methicillin-resistant staphylococci are mainly observed following clean surgery, and especially clean prosthetic operations, such as orthopedic or cardiothoracic surgical procedures, and are rarely found in deep and organ space infections following colorectal surgery. ${ }^{33}$

\section{Antimicrobial prophylaxis in colorectal surgery}

It is universally accepted that antibiotic prophylaxis, ie, perioperative administration of suitable antimicrobial agents, must be considered one of the most important measures in order to prevent SSI in colorectal surgery. In 1981, Baum and colleagues compared the incidence of wound infection and mortality rates of patients given antimicrobial prophylaxis for colorectal surgery with those of controls not given antimicrobial agents. By pooling data from 26 trials published from 1965 to 1980, they found that the wound infection rate was significantly higher in the control group, with $36 \%$ of patients developing SSI compared with $22 \%$ in the prophylactic antibiotic given group. ${ }^{18}$ Therefore, these authors recommended that no further trials of antimicrobial prophylaxis versus placebo be performed in colorectal surgery. However, despite the recommendation of Baum and colleagues, at least an additional four placebo-controlled studies have been published since 1981. ${ }^{34-37}$ All found that SSI rates were significantly lower in the antibiotic-treated groups $(12.9 \%$ versus $40.2 \%$ on pooled data from the four studies; pooled odds ratio $=0.24 ; 95 \%$ confidence interval [CI]: 0.13, 0.43).

Antimicrobial prophylaxis in colorectal operations can be done by administering antimicrobial agents either orally or systemically. The mechanisms of prophylaxis for oral and systemic regimens are quite different. The most important effect of the oral regimens is to reduce quantitatively the microbial flora of the digestive tract before operation. Parenteral systemic antibiotics, on the contrary, although certainly able to change the colonic microflora, ${ }^{38}$ have less impact on the quantity of aerobic and anaerobic bacteria within the large bowel at the time of operation, especially if single-dose prophylaxis is administered. Indeed, the proven efficacy of perioperative systemic antimicrobial agents is mainly related to the suppression of bacterial growth in the tissues of the operative field once contamination occurred. However, the aim of systemic prophylaxis is not the sterilization of the tissues in case of contamination, but rather to facilitate the function of the patient immune defense mechanisms by suppressing, or at least decreasing, bacterial growth in the surgical site. The two different mechanisms can also be combined by giving antimicrobial agents both orally and intravenously. Worldwide, there is a general consensus on the administration of prophylactic antibiotics intravenously; however, especially in North America, many colorectal surgeons - up to $88 \%$ by $1990,{ }^{39} 86.5 \%$ by $1997,{ }^{40}$ and up to $75 \%$ by $2003^{41}$ - prefer to administer a combined prophylaxis, ie, to give both oral and parenteral antibiotics.

As for the choice of antimicrobial agents for prophylaxis in colorectal surgery, there is a general agreement that antibiotic choices that cover both anaerobic and aerobic bacteria give the best results. Indeed, published trials show that the addition of an antibiotic covering aerobic intestinal flora in patients receiving an antimicrobial agents that cover anaerobic bacteria significantly reduced the incidence of SSIs. ${ }^{42}$ In the same way, the addition of an anaerobic coverage to aerobic coverage also resulted in a statistically significant reduction in SSI rate. ${ }^{42}$

In 1998, Song and Glenny ${ }^{43}$ published a systematic review of 147 randomized trials in colorectal surgery in which more than 70 different antibiotic regimens were tested. The main conclusions of the authors were that antimicrobial prophylaxis is effective for the prevention of SSIs in colorectal surgery and that there are no significant differences in the prophylactic efficacy among the different antimicrobials studied. Furthermore, they found that a single-dose or shortterm regimen is as efficacious as long-term, postoperative administration of antimicrobial agents and that no significant difference in the rate of SSI can be found between a single-dose regimen and a multidose regimen. Finally, no additional benefit could be observed in six trials in which parenteral alone were compared with parenteral plus oral prophylactic antibiotics. However, combined prophylaxis in colorectal surgery has been studied in several other trials published after the 1998. Results of these studies are conflicting. In a double-blind, placebo-controlled, randomized study on 215 patients undergoing elective colorectal surgery published by Lewis in 2002, combined oral and 
systemic antibiotics (neomycin and metronidazole orally + amikacin and metronidazole intravenously) were found to be superior to systemic antibiotics alone (amikacin and metronidazole) in preventing SSIs. ${ }^{44}$ These conclusions were also supported by a meta-analysis on combined oral and systemic antibiotics versus systemic antibiotic alone performed by Lewis on his own study plus 12 other randomized clinical studies published from 1975 to $1995 .{ }^{44}$ On the contrary, no difference in SSI rate was found by Espin-Basany and colleagues in a study of 300 patients undergoing elective colorectal resection who received three doses of cefoxitin intravenously and who were randomized to receive either three doses of oral antibiotics (neomycin and metronidazole) or one dose of oral antibiotics or no oral antibiotics. ${ }^{45}$ Recently, Kobayashi and colleagues found no advantage in the prevention of SSI by adding oral antibiotics to intravenous antimicrobial prophylaxis in colorectal surgery on 491 patients. ${ }^{46}$ Nelson and colleagues recently published a systematic review on antibiotic prophylaxis in colorectal surgery including 182 randomized controlled trials with more than 30,800 patients and 50 different antibiotics focused on a single outcome, which was the infection of the abdominal surgical wound. ${ }^{42}$ Meta-analyses performed in this study confirmed no statistically significant differences when comparing short- or long-term duration of prophylaxis or single dose versus multiple dose antibiotics. It was also found that antibiotic regimens should include cover against both aerobic and anaerobic bacteria. Finally, a statistically significant benefit in favor of combined oral and intravenous dosing when compared to intravenous alone (relative risk [RR] 0.55, 95\% CI: $0.41-0.74$ ) or oral alone (RR 0.34, 95\% CI: 0.13-0.87) was shown in thirteen reports including 2,362 patients and three studies (283 patients), respectively.

However, it should be noted that the use of oral antibiotics increase the incidences of gastrointestinal adverse effects including nausea, vomiting, abdominal pain, diarrhea, and Clostridium difficile colonization and infection..$^{45,47-49}$ In a study of 300 patients who received three doses of intravenous cefoxitin and who were randomized to receive either three doses (Group A), one dose (Group B), or no oral antibiotics (neomycin and metronidazole) (Group C), vomiting occurred in $31 \%, 11 \%$, and $9 \%$ of the patients (Groups A, B, and C, respectively, $P<0.001$ ); nausea was present in $44 \%, 18 \%$, and $13 \%$ of patients $(P<0.001)$, and abdominal pain was recorded in $13 \%, 10 \%$, and $4 \%$ of patients $(P<0.077) .{ }^{45}$ In another randomized comparative study of 137 patients receiving oral, systemic, or combined prophylaxis, no significant differences in the incidence of SSI among the three groups were found, but the oral antibiotic regimen induced a greater change in the intestinal flora and was associated with more frequent postoperative diarrhea. ${ }^{48}$ In another trial ${ }^{49}$ the rate of $C$. difficile infection was higher in patients who received combined prophylaxis (7.4\%) compared with patients who received only parenteral antibiotics $(2.6 \% ; P=0.03)$. However, all the patients enrolled in these studies received also mechanical bowel preparation (MBP), and it is well known that mechanical cleansing takes part in altering the normal enteric flora, increasing the risk of intestinal adverse events and $C$. difficile infection. The matter is even more complicated because mechanical bowel preparation has universally been adopted for patients undergoing colorectal surgery and is not based on well designed prospective randomized studies, but based only on observational data and expert opinions, ${ }^{50}$ and its role in lowering the rate of postoperative SSIs has been questioned by several recent studies. ${ }^{50-52}$ In two recent reviews, which included 13 and 14 controlled trials with 4,777 and 4,859 patients, respectively, Guenaga and colleagues $^{53}$ and Slim and colleagues ${ }^{54}$ did not find any differences in SSIs and anastomotic leakage between the groups of patients who received MBP or had no preparation. If the practice of MBP is abandoned, the entire matter of oral prophylaxis in colorectal surgery including number of doses and administration timing needs to be re-evaluated. Furthermore, it is not known whether oral antibiotics would be still effective when the colon is not empty.

In conclusion, the use of antibiotic prophylaxis for patients undergoing colorectal surgery is imperative and some principles appear to be firmly stated: antibiotics should include coverage of both aerobic and anaerobic bacteria. For intravenous antibiotics, they must be administered only once before surgery. Several different antibiotics have been studied as parenteral prophylactic regimens in colorectal surgery with similar estimates of efficacy. It is therefore very difficult, if not impossible, to identify the best one. ${ }^{43}$ However, some parenteral antibiotic regimens, such as intravenous cefoxitin or cefotetan, are so broadly used as to be considered as gold standard, and to which other antibiotic choices should be compared. ${ }^{42,55-60}$

In the light of the more recent data against MBP, further studies seem instead necessary in order to firmly ascertain the role and the time of administration of oral antibiotics, whether administered alone or as combined prophylactic regimens, as oral antibiotics have not been studied in the uncleansed colon. Further research on adverse events of 
antibiotic prophylaxis, especially $C$. difficile colonization and infection, in patients submitted to MBP versus no preparation, is also warranted.

\section{Major properties of ertapenem In vitro activity}

Three multicenter studies on more than 10,000 recent clinical isolates, examining broad ranges of bacterial species from US, Europe, and Australia ${ }^{61-63}$ have so far been published on the in vitro activity of ertapenem, a parenteral broad-spectrum 1-beta-methyl-carbapenem. According to the British Society for Antimicrobial Chemotherapy, breakpoints of susceptibility and resistance are $<2 \mathrm{mg} / \mathrm{L}$ and $>2 \mathrm{mg} / \mathrm{L}$, respectively, for all species except pneumococci, where ertapenem has values of $\leq 1 \mathrm{mg} / \mathrm{L}$ and $>1 \mathrm{mg} / 1$, respectively. ${ }^{64}$

With rare exceptions, the minimum inhibitory concentrations (MICs) for Enterobacteriaceae fall between $0.008 \mathrm{mg} / \mathrm{L}$ and $0.12 \mathrm{mg} / \mathrm{L}$. On the contrary, ertapenem has only very limited activity against Pseudomonas aeruginosa isolates (with MICs ranging from $2 \mathrm{mg} / \mathrm{L}$ to $16 \mathrm{mg} / \mathrm{L}$ ), and Acinetobacter spp (MICs generally exceeding $4 \mathrm{mg} / \mathrm{L}$ ), and lacks activity against Stenotrophomonas maltophilia. As for Gram-positive microorganisms, ertapenem is active against both methicillin-susceptible Staphylococcus aureus and methicillin-susceptible coagulase negative staphylococci (with MICs ranging from $0.12 \mathrm{mg} / \mathrm{L}$ to $0.5 \mathrm{mg} / \mathrm{L}$ ), Propionibacterium acnes and most Corynebacterium spp, but has no activity against Enterococcus faecalis, Enterococcus faecium, and methicillin-resistant staphylococci. The activity against pneumococci is good, although sensitivity, as with all $\beta$-lactams, is reduced for penicillin nonsusceptible isolates. The activity against anaerobes is excellent: MICs of $1-2 \mathrm{mg} / \mathrm{L}$ have been found for Bacteroides fragilis group isolates, and virtually all Prevotella, Fusobacterium, Peptostreptococcus, and Porphyromonas spp. are susceptible at $\leq 0.5 \mathrm{mg} / \mathrm{L}$. Most clostridia, including Clostridium difficile, are susceptible at $1-2 \mathrm{mg} / \mathrm{L}$.

\section{Pharmacokinetics and pharmacodynamics}

The plasma half-life of ertapenem in healthy volunteers is approximately four hours, allowing once-daily administration. ${ }^{65}$ This long half-life reflects binding to plasma proteins. Indeed, $84 \%-96 \%$ of ertapenem is bound to plasma protein and this protein binding decreases as plasma concentrations of ertapenem increase. ${ }^{65}$ Only the unbound fraction of the drug can penetrate into the tissues; therefore only $4 \%-16 \%$ of the mean plasma concentration is responsible for the antmicrobial activity of ertapenem. Plasma concentrations of total drug with a daily dose of $1 \mathrm{~g}$ exceed the $\mathrm{MIC}_{90}$ for susceptible bacteria through most of the dosing interval, and free drug concentrations remains above the $\mathrm{MIC}_{90}$ for approximately six hours. ${ }^{66}$

About $80 \%$ of excretion is via the kidneys, with half as native compound. A further $10 \%$ is eliminated via the feces. If the creatinine clearance is $\leq 30 \mathrm{ml} / \mathrm{min} / 1.73 \mathrm{~m}^{3}$, halving of the dose is suggested in the US, whereas in Europe it is suggested that ertapenem should not be administered at all. On the other hand, no adjustment is required for hepatic insufficiency, because ertapenem does not undergo either hepatic metabolism or significant biliary excretion.

Intra-abdominal tissue penetration of $1 \mathrm{~g}$ ertapenem has been studied in 48 patients requiring abdominal surgery. ${ }^{67}$ The mean tissue concentration in the gall bladder $(16.0 \pm$ $8.8 \mathrm{mg} / \mathrm{kg})$, colon $(12.1 \pm 5.3 \mathrm{mg} / \mathrm{kg})$, small bowel $(7.0 \pm 5.7 \mathrm{mg} / \mathrm{kg})$, liver $(4.5 \pm 2.3 \mathrm{mg} / \mathrm{kg})$, and pancreas $(3.4 \pm 2.9 \mathrm{mg} / \mathrm{kg}$ ) were above MICs for susceptible bacteria usually found in intra-abdominal infections, including E. coli, Enterobacteriaceae, and B. fragilis. Furthermore, the mean tissue/plasma ratio was 0.19 for the colon, 0.17 for the small bowel and gall bladder, 0.088 for the liver and 0.095 for the pancreas. Ertapenem's concentrations in intraabdominal tissues at $25 \%$ of dosing interval (ie, six hours after administration) were at least 1.5 times above the MICs for susceptible bacteria usually found in intra-abdominal infections, and three times for B. fragilis, and 10 times for $E$. coli.

\section{Therapeutic use}

Ertapenem is licensed in Europe for the treatment of intra-abdominal and gynecological infections, communityacquired pneumonia, and diabetic foot infections (without osteomyelitis). In the US and other countries it is also registered for skin and skin structure infections and for complicated urinary tract infections. Actually, major clinical trials in the above indications showed equivalence of ertapenem to comparators, ie, cefriaxone + metronidazole ${ }^{68}$ and piperacillin/tazobactam ${ }^{69}$ in the treatment of intra-abdominal and acute pelvic infections, ${ }^{70}$ ceftriaxone in communityacquired pneumonia, ${ }^{71}$ piperacillin/tazobactam in skin and skin structure infections, ${ }^{72}$ and ceftriaxone in complicated urinary tract infections. ${ }^{73,74}$ No serious side effects occurred in these trials. However, the intestinal adverse events observed are noteworthy: overall, diarrhea occurred in $1.7 \%-7 \%$ of ertapenem patients, and two out of 203 and two out of 274 patients treated with ertapenem displayed either $C$, difficile-associated diarrhea or pseudomembranous 
colitis in trials on intra-abdominal infections ${ }^{70}$ and skin and soft tissue infections, ${ }^{73}$ respectively.

On the basis of its spectrum of activity, encompassing both aerobes and anaerobes, ertapenem must be considered to be mainly indicated in the treatment of complex mixed infections, and particularly of intra-abdominal infections acquired in the community, where Acinetobacter spp and $P$. aeruginosa are uncommon pathogens. However, owing to the long half-life, ertapenem could also be suitable as a single-dose prophylaxis in those surgical procedures, such as colorectal surgery, where prophylaxis must cover both anaerobic and aerobic bacteria.

\section{Antibiotic prophylaxis} with ertapenem in colorectal surgery

Aiming to find a possible parenteral antibiotic alternative to cefoxitin and cefotetan, whose manufacturers seem to be planning to discontinue the production, ${ }^{75}$ Itani and colleagues assessed the efficacy and safety of antibiotic prophylaxis with ertapenem as compared with cefotetan in patients undergoing elective colorectal surgery. ${ }^{75}$ Ertapenem was chosen in the light of its appropriate coverage against potential pathogens, attractive pharmacokinetic and pharmacodynamic characteristics, and results of previous clinical studies.

In this prospective, double-blind, randomized, industry sponsored study, conducted between May 2002 and March 2005 at 51 centers in the United States, patients aged 18 years or older who were scheduled to undergo elective open surgery of the colon or rectum, and had sufficient time for MBP (sodium phosphate or polyethylene glycol), were randomly assigned in a 1:1 ratio to the study groups. They were given either a single dose of $1 \mathrm{~g}$ ertapenem or $2 \mathrm{~g}$ cefotetan, which were infused over a 30-minute period within 60 minutes before the initial surgical incision was made. Patients were stratified according to whether the surgery was to include a resection of any portion of the rectum. The primary efficacy endpoint was the proportion of patients who could be evaluated and for whom prophylaxis was successful at the four-week follow-up assessment after surgery. Success was defined as no signs or symptom of infection at the surgical site, no anastomotic leakage, and no further need for surgery or antibiotic use for any reason. Treatment was considered to have failed, in addition to the above mentioned criteria, if a patient was treated with antibiotics for a distant site infection - even in the absence of signs or symptoms of surgical site infection - or missed the four-week assessment. To qualify for inclusion in the modified intention to treat analysis, patients were required to have undergone elective open colorectal surgery with standard MBP and to have received a dose of a study drug. In the per-protocol analysis were included patients who, in addition to the above criteria, have received a study drug within two hours before surgical incision and six hours before surgical closure, and have undergone the fourweek follow-up assessment. All the adverse events were collected until 14 days after the administration of antibiotic prophylaxis.

Of the 1,002 patients enrolled, 901 (451 in the ertapenem group and 450 in the cefotetan group) were included in the intention-to-treat analysis, and 672 (338 in the ertapenem group and 334 in the cefotetan group) were included in the per-protocol analysis. After adjustment for strata, in the modified intention to treat analysis the rate of overall prophylactic failure was $40.2 \%$ in the ertapenem group and $50.9 \%$ in the cefotetan group (absolute difference, $-10.7 \%$, $95 \%$ CI: -17.1 to -4.2 ). In the per-protocol analysis, the failure rate was $28.0 \%$ in the ertapenem group and $42.8 \%$ in the cefotetan group (absolute difference, $-14.8 \%$; 95\% CI: -21.0 to -7.5 ). In the group of patients who underwent surgical procedures which did not include resection of rectum (253 patients receiving ertapenem and 265 patients receiving cefotetan) clinical failure occurred in $26.9 \%$ of patients treated with ertapenem and $43.4 \%$ of patients in the cefotetan group (absolute difference, $-16.5 \%, 95 \% \mathrm{CI}$ : -24.5 to -8.3 ). In the patients who underwent surgical procedures including resection of rectum ( 85 and 69 patients receiving ertapenem and cefotetan, respectively) clinical failure occurred in $31.8 \%$ of patients in the ertapenem group and $40.6 \%$ of those receiving cefotetan (absolute difference, $-8.8 \% ; 95 \%$ CI: -23.9 to -6.4$)$. Both the intention-to-treat analysis and the per-protocol analysis fulfilled statistical criteria for the superiority of ertapenem. In the modified intention-to-treat analysis, the most common reason for failure of prophylaxis at the four-week assessment after surgery in both groups of patients was surgical site infection, which was $17.1 \%$ in the ertapenem group (12.3\% superficial incisional infection, $3.3 \%$ deep incisional infection, $1.5 \%$ organ-space infection), and $26.2 \%$ in patients receiving cefotetan (17.9\% superficial incision infection, $5.1 \%$ deep incisional infection, 3.2\% organ-space infection) (absolute difference, $-9,1 ; 95 \%$ CI: $-14,4$ to -3.7$)$.

None of the safety end points differed significantly between the two study groups. However, the overall incidence of diarrhea was 5.7\% (27 out of 476) in the ertapenem group and $3.2 \%$ (15 out of 476$)$ in the cefotetan group $(P=0.08)$. Furthermore, $C$. difficile infection occurred in eight of 
476 patients in the ertapenem group $(1.7 \%)$ and in three of 476 patients $(0.6 \%)$ in the cefotetan group $(P=0.22)$.

An analysis of the microorganisms isolated in the failures of prophylaxis, with a correlation with the clinical outcomes reported by Itani and colleagues, was recently performed by Goldstein and colleagues. ${ }^{76}$ The in vitro activity of ertapenem was found to be superior to that of cefotetan against all anaerobic and many aerobic bacteria isolated from postoperative cultures of patients who failed prophylaxis. Indeed, of the 216 aerobes tested, $62.6 \%$ were resistant to cefotetan and $44 \%$ to ertapenem, and approximately half of the 158 anaerobes $(50.7 \%)$ were resistant to cefotetan, being resistant to ertapenem only one anaerobe (Desulfobrivio fairfieldensis), isolated from a superficial incision infection. Furthermore, no ertapenem-resistant enteric microorganisms were isolated.

The potential cost impact of using ertapenem $1 \mathrm{~g}$ versus cefotetan $2 \mathrm{~g}$ as prophylaxis for elective open colorectal surgery was assessed in another post-hoc study by Wilson and colleagues in the patients included in the per-protocol analysis of the study by Itani and colleagues (338 in the ertapenem group and 334 in the cefotetan group). ${ }^{77}$ The mean \pm standard deviation length of stay for all patients, including both prophylactic successes and failures, was $7.6 \pm 6.6$ days for ertapenem and $8.7 \pm 9.5$ days for cefotetan. The overall mean per-patient cost of prophylactic drug and hospitalization room and board was US\$15,245 with ertapenem and US\$17,428 with cefotetan. A net saving of US $\$ 2,183$ per patient with ertapenem relative to cefotetan prophylaxis was therefore found in prophylactic antibiotic drug and hospital costs.

\section{Discussion}

The original purpose of the study by Itani and colleagues was to demonstrate the noninferiority of ertapenem as compared with one conventional antibiotic (cefotetan), as a parenteral prophylactic agent in colorectal surgery. However, at the four-week assessment after surgery, ertapenem was found to be superior in terms of the overall proportion of favorable clinical responses and the incidence of postoperative SSIs. Furthermore, ertapenem prophylaxis resulted in a shorter average length of stay, with a saving of more than US $\$ 2,000$ per patient relative to cefotetan. It is surprising that, in the per-protocol analysis, the overall rates of prophylactic failures and of surgical-site infection in the cefotetan group were approximately $43 \%$ and $31 \%$, respectively. These rates are much higher than the reported ranges of failures found in previous studies of cefotetan prophylaxis in colorectal surgery.
Indeed, as the authors noted, in nine previous clinical trials of cefotetan prophylaxis in colorectal surgery the reported rates of surgical-site infections ranged from $9.4 \%$ to $28.0 \%$, with a mean of $17.1 \%{ }^{78-86}$ This discrepancy can be explained at least in part by the inclusion of unexplained antibiotic use and anastomotic leakage, in addition to surgical site infections, in the failures of prophylaxis (7.5\% and $4.2 \%$, respectively). As for the high rate of superficial-site infection observed in the study by Itani and colleagues $(22.4 \%$ in cefotetan group and $13.1 \%$ in ertapenem group), it should be noted that $28.9 \%$ of the patients evaluated had a body mass index (BMI) $\pm 30 \mathrm{~kg} / \mathrm{m}^{2}$, which is much higher of the rates of obese patients usually included in other studies. ${ }^{82,83,86}$ Furthermore, in a post-hoc analysis performed using the data from the study by Itani and colleagues, the incidence of SSIs, and specifically of superficial incisional SSIs, was found to be higher in patients with a BMI $\pm 30 \mathrm{~kg} / \mathrm{m}^{2}$ regardless of the prophylactic antibiotic (ertapenem or cefotetan) given. ${ }^{87}$ Indeed, failure of antibiotic surgical prophylaxis in obese patients may be related both to technical factors, such as an inadequate obliteration of "dead spaces," and to low drug levels in serum and tissues, especially at the end of an operation and during surgery. ${ }^{88}$ The possible occurrence of other surgical-related factors that could have contributed to the high rates of SSIs, such as failure to maintain normothermia, and uncontrolled hyperglycemia in the perioperative period, ${ }^{89}$ have not been analyzed in the study by Itani and colleagues. Finally, the high rates of resistance to cefotetan of microorganisms isolated in the failures of prophylaxis, seen in the post-hoc study by Goldstein and colleagues ${ }^{76}$ (62.6\% and 50.7\% for aerobes and anaerobes, respectively), could have been a direct consequence of the repeated use of cefotetan as surgical prophylaxis in the centers participating in the study.

From the prophylactic, economic, and bacteriological points of view, ertapenem was found to be more effective than cefotetan in elective, open, colorectal surgery prophylaxis. On the basis of these results, ertapenem has been approved by the US Food and Drug Administration (FDA) and European Medicines Agency (EMEA) in the US and Europe, respectively, for the prophylaxis of SSI following elective colorectal surgery in adults. It is reasonable to wonder whether ertapenem should be considered the preferred antimicrobial agent for prophylaxis in colorectal surgery. However, three major considerations should be made on this subject prior to translation of this study's conclusions in extensive clinical practice. First, several antibiotic regimens have been found not inferior to cefotetan in colorectal 
surgery prophylaxis, ${ }^{43}$ and, so far, we do not have data that directly compare ertapenem with these antimicrobial agents. In comparing the relative efficacy of different antimicrobial agents in colorectal surgery prophylaxis, considerable discrepancies have been shown to exist between the direct and the indirect comparisons. ${ }^{90}$ Therefore we must be very cautious in extrapolating the relative prophylactic efficacy of different antimicrobial regimens by comparing the results of this trial with studies of other antimicrobial agents. ${ }^{91}$ The second important consideration is whether the extensive use of carbapenem predisposes patients and the community to the emergence of resistant microorganisms. Carbapenem resistance is a serious problem because imipenem and meropenem are the last resort against serious infections caused by multiresistant aerobic Gram-negative bacteria that produce extended spectrum beta-lactamases. Whether it is right to fear ertapenem as a major inducer of resistance is, however, less certain. Most carbapenem resistance is in nonfermenters, such as Pseudomonas spp and Acinetobacter spp, and these microorganisms are outside the spectrum of ertapenem. Furthermore, it has been found that bowel colonization with carbapenem-resistant Gram-negative bacilli is rarely observed following ertapenem treatment of intraabdominal infections, ${ }^{92}$ and it is difficult to find carbapenem resistance in Enterobacteriaceae, as demonstrated by its rarity many years after the launch of imipenem. ${ }^{64}$ It is certainly true that a single-dose antimicrobial prophylaxis is less likely to induce the emergence of drug-resistant microorganisms than is repeated administration. However, it should be noted that surgeons often prolong the duration of antimicrobial prophylaxis into the postoperative period, ${ }^{41}$ and the common experience shows that widespread use of any antimicrobial agent is followed, sooner or later, by the emergence of antimicrobial resistance to that antibiotic. The third important consideration that should be made prior to the translation of the study by Itani and colleagues into extensive clinical practice refers to the ertapenem effects on the intestinal gut flora. Indeed, the higher incidence of $C$. difficile infection in the ertapenemtreated patients, even though not statistically significant, is a deep concern. C. difficile associated disease (CDAD) has been recognized as a nosocomial problem for more than 30 years, ${ }^{93}$ especially in surgical and critical ill patients, but the epidemiology of the disease is changing. The prevalence and the severity of CDAD continue to increase despite numerous discoveries concerning its epidemiology and the pathogenicity of $C$. difficile..$^{94,95}$ This increasing trend is associated with the emergence and spread of an epidemic strain referred to as NAP1/BI (North American pulsed-field type 1, ribotype 027 , restriction endonuclease analysis type BI, toxinotype III). ${ }^{96,97}$ As a result, the average hospital cost of CDAD patients is estimated to be $54 \%$ more that non-CDAD patients in the US, ${ }^{98}$ and length of hospital stay of CDAD patients also increases, ranging from an average of 3.6 days for the total patient population to 16 days for surgical inpatients. ${ }^{99}$ Several years ago we showed that $C$. difficile colonization can be induced also by single-dose antibiotic prophylaxis in surgery, suggesting that, when a comparable efficacy in preventing postoperative infections is proven for different antimicrobial agents, the rate of $C$. difficile colonization and disease should be taken into account in the choice of the most suitable agent for surgical prophylaxis..$^{38}$ In our opinion these suggestions are even more important today on the basis of the increasing prevalence and severity of C.difficile infection.

\section{Conclusions}

The clinical superiority of ertapenem $1 \mathrm{~g}$ over cefotetan $2 \mathrm{~g}$ for the prevention of SSIs following elective colorectal surgery was clearly demonstrated in a well designed and well controlled study. Given that single-dose cefotetan is so broadly used as a parenteral prophylactic agent in colorectal operations, should single-dose ertapenem be considered as the "gold standard" prophylactic regimen for elective colorectal surgery on the basis of this study? In other words, is ertapenem better that commonly used prophylactic regimens other than cefotetan for the prevention of SSI following colorectal operations? And, if so, does prophylaxis outweigh the risk of aggravate antimicrobial resistance and intestinal side effects of antimicrobial prophylaxis including $C$. difficile infection? These important questions will be answered by further comparative studies of ertapenem prophylaxis versus other widely used prophylactic regimens for colorectal surgery in patients submitted to MBP versus no preparation, as well as further research on adverse events of antibiotic prophylaxis, including the emergence of resistance and C. difficile colonization and infection.

\section{Disclosure}

The author reports no conflicts of interest in this work.

\section{References}

1. Mangram AJ, Horan TC, Pearson ML, Silver LC, Jarvis WR. Guideline for prevention of surgical site infection. Hospital Infection Control Practices Advisory Committee. Infect Control Hosp Epidemiol. 1999;20:250-278.

2. Dimick JB, Chen SI, Taheri PA, Henderson WG, Khuri SF, Campbell DA Jr. Hospital costs associated with surgical complications: a report from the private-sector National Surgical Quality Improvement Program. J Am Coll Surg. 2004;199:531-537. 
3. Khan NA, Quan H, Bugar JM, Lemaire JB, Brant R, Ghali WA. Association of postoperative complications with hospital costs and length of stay in a tertiary care center. $J$ Gen Intern Med. 2006;21: $177-180$

4. Dimick JB, Pronovost PJ, Cowan JA, Lipsett PA. Complications and costs after high-risk surgery: where should we focus quality improvement initiatives? J Am Coll Surg. 2003;196:671-678.

5. Zhan C, Miller MR. Excess length of stay, charges and mortality attributable to medical injures during hospitalization. JAMA. 2003;290 1868-1874.

6. Fleischman KE, Goldman I, Young B, Lee TH. Association between cardiac and noncardiac complications in patients undergoing noncardiac surgery: outcomes and effects on length of stay. Am J Med. 2003;115:515-520.

7. Di Piro JT, Martindale RG, Bakst A, Vacani PF, Watson P, Miller MT. Infection in surgical patients: effects on mortality, hospitalization and postdischarge care. Am J Health Syst Pharm. 1998;55:777-781.

8. Kirkland KB, Briggs JP, Trivette SI, Wilkinson WE, Sexton DJ. The impact of surgical site infections in the 1990s: attributable mortality, excess length of hospitalization, and extra costs. Infect Control Hosp Epidemiol. 1999;20:725-730.

9. Haley RW, Scabergh DR, Crossley KB, Von Allmen SD, McGowan JE Jr. Extra charges and prolongation of stay attributable to nosocomial infections: a prospective interhospital comparison. Am J Med. 1981; 70:51-58.

10. Eagye KJ, Nicolau DP. Deep and organ/space infections in patients undergoing elective colorectal surgery: incidence and impact on hospital length of stay and costs. Am J Surg. 2009;198(3):359-367.

11. Smith RL, Bohl JK, McElearney ST, et al. Wound infection after colorectal resection. Ann Surg. 2004;239:599-607.

12. Horan TC, Gaynes RP, Martone WJ, Jarvis WR, Emori TG. CDC definitions of nosocomial surgical site infections, 1992: a modification of CDC definitions of surgical wound infections. Infect Control Hosp Epidemiol. 1992;13:606-608.

13. Horan TC, Culver DH, Gaynes RP, Jarvis WR, Edwards JR, Reld CR. Nosocomial infections in surgical patients in the United States, January 1986-June 1992. National Nosocomial Infections Surveillance (NNIS) System. Infect Control Hosp Epidemiol. 1993;14:73-80.

14. Vegas AA, Jodra VM, Garcia ML. Nosocomial infections in surgical wards: a controlled study of increased duration of hospital stays and direct cost of hospitalization. Eur J Epidemiol. 1993;9:504-510.

15. Nichols RL. Preventing surgical site infections: a surgeon's perspective. Emerg Infect Dis. 2001;7:220-224.

16. Emori TG, Gaynes RP. An overview of nosocomial infections, including the role of the microbiology laboratory. Clin Microbiol Rev. 1993;6:438-442.

17. Leaper DJ, van Goor H, Reilly J, et al. Surgical site infection a European perspective of incidence and economic burden. Int Wound J. 2004;1:247-273.

18. Baum ML, Anish DS, Chalmers TC, Sacks HS, Smith H Jr, Fagerstrom RM. A survey of clinical trials of antibiotic prophylaxis in colon surgery: evidence against further use of no-treatment controls. N Engl J Med. 1981;305:795-799.

19. Berard F, Gandon J. Postoperative wound infections: the influence of ultraviolet irradiation of the operating room and various other factors. Ann Surg. 1964;160(Suppl 2):1-192.

20. Krizek TJ, Robson MC. Evolution of quantitative bacteriology in wound management. Am J Surg. 1975;130:579-584.

21. Garibaldi RA, Cushing D, Lerer T. Risk factors for postoperative infection. Am J Med. 1991;91:158S-163S

22. Haley RW, Culver DH, Morgan WM, White JW, Emori TG, Hooton TM. Identifying patients at high risk of surgical wound infection. A simple multivariate index of patient susceptibility and wound contamination. Am J Epidemiol. 1985;121:206-215.

23. Allen DB, Maguire JJ, Mahdavian M, et al. Wound hypoxia and acidosis limit neutrophil bacterial killing mechanisms. Arch Surg. 1997;132:991-996.
24. Kurz A, Sessler DI, Lenhardt R. Perioperative normothermia to reduce the incidence of surgical wound infection and shorten hospitalization. Study of Wound Infection and Temperature Group. $N$ Engl J Med. 1996;334:1209-1215.

25. Gottrup F, Firmin R, Rabkin J, Halliday BJ, Hunt TK. Directly measured tissue oxygen tension and arterial oxygen tension assess tissue perfusion. Crit Care Med. 1987;15:1030-1036.

26. Hopf HW, Hunt TK, West JM, et al. Wound tissue oxygen tension predicts the risk of wound infection in surgical patients. Arch Surg. 1997;132:997-1004.

27. Kaye KS, Schmit K, Pieper C, et al. The effect of increasing age on the risk of surgical site infection. $J$ Infect Dis. 2005;191:1056-1062.

28. Woodfield JC, Beshay NM, Pettigrew RA, Plank LD, van Rij AM. American Society of Anesthesiologists classification of physical status as a predictor of wound infection. Anz J Surg. 2007;77:738-741.

29. Choban PS, Heckler R, Burge JC, Flanebaum L. Increased incidence of nosocomial infection in obese surgical patients. Am Surg. 1995; 61:1001-1005.

30. Sutter VI. Frequency of occurrence and antimicrobial susceptibility of bacterial isolates from intestinal and female genital tracts. Rev Infect Dis. 1983;5(Suppl 1):S84-S89.

31. Barie PS. Emerging problems in Gram-positive infections in the postoperative patients. Surg Gynecol Obstet. 1993;177(Suppl):S55-S64.

32. Rovera F, Diurni M, Dionigi G, et al. Antibiotic prophylaxis in colorectal surgery. Expert Rev Anti Infect Ther. 2005;3:787-795.

33. Engemann JJ, Carmeli Y, Cosgrove SE, et al. Adverse clinical and economic outcomes attributable to methicillin resistance among patients with Staphylococcus aureus surgical site infection. Clin Infect Dis. 2006;36:592-598.

34. Gomez-Alonzo A, Lozano F, Perez A, Almazan A, Abdel-Lah A, Cuadrado F. Systematic prophylaxis with gentamicin-metronidazole in appendicectomy and colorectal surgery: a prospective controlled clinical study. Int Surg. 1984;69:17-20.

35. Gottrup F, Diederich P, Sorensen K, Nielson SV, Ornsholt J, Brandsborg O. Prophylaxis with whole gut irrigation and antimicrobials in colorectal surgery: a prospective, randomised double-blind clinical trial. Am J Surg. 1985;149:317-322.

36. Schiessel R, Huk I, Wunderlich M, Rotter M, Werwalka G, Schemper M. Postoperative infections in colonic surgery after enteral bacitracinneomycin-clindamycin or parenteral mezlocillin-oxacillin prophylaxis. J Hosp Infect. 1984;5:289-297.

37. Utley RJ, Macbeth WA. Peroperative cefoxitin: a double-blind prospective study in the prevention of wound infection. J R Coll Surg Edinb. 1984;29:143-146.

38. Privitera G, Scarpellini P, Ortisi G, Nicastro G, Nicolin R, de Lalla F. Prospective study of Clostridium difficile intestinal colonization and disease following single-dose antibiotic prophylaxis in surgery. Antimicrob Agents Chemother. 1991;35:208-210.

39. Solla JA, Rothenberger D. Preoperative bowel preparation. A survey of colon and rectal surgeons. Dis Colon Rectum. 1990;33:154-159.

40. Nichols RL, Smith JW, Garcia R, Waterman RS, Holmes JW. Current practices of preoperative bowel preparation among North American colorectal surgeons. Clin Infect Dis. 1997;24:609-619.

41. Zmora O, Wexsner SD, Hajjar L, et al. Trends in preparation for colorectal surgery: survey of the members of the American Society of colon and rectal surgery. Am J Surg. 2003;69:154-160.

42. Nelson RL, Glenny AM, Song F. Antimicrobial prophylaxis for colorectal surgery. Cochrane Database Syst Rev. 2009;1:CD001181.

43. Song F, Glenny AM. Antimicrobial prophylaxis in colorectal surgery: a systematic review of randomised controlled trials. Health Technol Assess. 1998;2(7):1-110.

44. Lewis RT. Oral versus systemic antibiotic prophylaxis in elective colon surgery: a randomized study and meta-analysis send a message from the 1990s. Can J Surg. 2002;45:173-180.

45. Espin-Basany E, Sanchez-Garcia JL, Lopez-Cano M, et al. Prospective, randomised study on antibiotic prophylaxis in colorectal surgery. It is really necessary to use oral antibiotics? Int J Colorectal Dis. 2005;20:542-546. 
46. Kobayashi M, Mohri Y, Tonouchi H, et al. Randomized clinical trial comparing intravenous antimicrobial prophylaxis alone with oral and intravenous antimicrobial prophylaxis for the prevention of a surgical site infection in colorectal cancer surgery. Surg Today. 2007;37:383-388.

47. Peruzzo L, Savio S, de Lalla F. Systematic versus systematic plus oral chemoprophylaxis in elective colorectal surgery. Chemioterapia. 1987;6:601-602.

48. Yabata E, Okabe S, Endo M. A prospective, randomized clinical trial of preoperative bowel preparation for elective colorectal surgery comparison among oral, systemic, and intraoperative luminal antibacterial preparations. J Med Dent Sci. 2007;44:75-80.

49. Wren SM, Ahmed N, Jamal A, Safadi BY. Preoperative oral antibiotics in colorectal surgery increase the rate of Clostridium difficile colitis. Arch Surg. 2005;140:752-756.

50. Wille-Jørgensen P, Guenaga KF, Matos D, Castro AA. Pre-operative mechanical bowel cleansing or not? An up-date meta-analysis. Colorectal Dis. 2005; 7:304-310.

51. Nelson R, Singer M. Primary repair for penetrating colon injuries. Cochrane Database Syst Rev. 2003;3:CD002247.

52. Bucher P, Mermillod B, Gervaz P, Morel P. Mechanical bowel preparation for elective colorectal surgery: a meta-analysis. Arch Surg. 2004;139:1359-1364.

53. Guenaga KK, Matos D, Wille-Jørgensen P. Mechanical bowel preparation for elective colorectal surgery. Cochrane Database Syst Rev. 2009; 1:CD001544.

54. Slim K, Vicaut E, Launay-Savary MV, Contant C, Chipponi J. Updated systematic review and meta-analysis of randomized clinical trials on the role of mechanical bowel preparation before colorectal surgery. Ann Surg. 2009;249:203-209.

55. Bratzler DW, Houck PM. Antimicrobial prophylaxis for surgery: an advisory statement from the National Surgical Infection Prevention Project. Clin Infect Dis. 2004;38:1707-1715.

56. Bratzler DW, Houck PM, Richards C, et al. Use of antimicrobial prophylaxis for major surgery: baseline results from the National Surgical Infection Prevention Project. Arch Surg. 2005;140:174-182.

57. Page CP, Bohnen JM, Fletcher JR, McManus AT, Solomkin JS, Wittmann DH. Antimicrobial prophylaxis for surgical wounds: guidelines for clinical care. Arch Surg. 1993;128:79-88.

58. Dellinger EP, Gross PA, Barrett TH, et al. Quality standard for antimicrobial prophylaxis in surgical procedures. The Infectious Diseases Society of America. Infect Control Hosp Epidemiol. 1994;15:182-188.

59. American Society of Health-System Pharmacists. ASHP therapeutic guidelines on antimicrobial prophylaxis in surgery. Am J Health Syst Pharm. 1999;56:1839-1888.

60. Gilbert DN, Moellering RC, Sande MA. The Sanford guide to antimicrobial therapy. 33rd ed. Hyde Park, VT: Antimicrobial Therapy; 2003. p. 123-124.

61. Livermore DM, Carter MW, Bagel S, et al. In vitro activities of ertapenem (MK-0826) against recent clinical bacteria collected in Europe and Australia. Antimicrob Agents Chemother. 2001;45:1860-1867.

62. Fuchs PC, Barry AL, Brown SD. In vitro activities of ertapenem (MK-0826) against clinical bacterial isolates from 11 North American medical centers. Antimicrob Agents Chemother. 2001;45:1915-1918.

63. Goldstein EJ, Citron DM, Merriam CV, Warren Y, Tyrrell K. Comparative in vitro activities of GAR-936 against aerobic and anaerobic animal and human bite wound pathogens. Antimicrob Agents Chemother. 2000;44:2747-2751.

64. Livermore DM, Sefton AM, Scott GM. Properties and potential of ertapenem. J Antimicrob Chemother. 2003;52:331-344.

65. Majumdar AK, Musson DG, Birk KL, et al. Pharmacokinetics of ertapenem in healthy young volunteers. Antimicrob Agents Chemother. 2002;46:3506-3511.

66. Nix DE, Majumdar AK, DiNubile MJ. Pharmacokinetics and pharmacodynamics of ertapenem :an overview for clinicians. J Antimicrob Chemother. 2004;53(Suppl S2):S23-S28.

67. Wittau M, Wagner E, Kaever V, Koal T, Henne-Bruns D, Isenmann R. Intraabdominal tissue concentration of ertapenem. J Antimicrob Chemother. 2006;57:312-316.
68. Yellin AE, Hassett JM, Fernandez A, et al; 004 Intra-abdominal Infection Study Group. Ertapenem monotherapy versus combination therapy with ceftriaxone plus metronidazole for treatment of complicated intra-abdominal infections in adult. Int J Antimicrob Agents. 2002;20: 165-173.

69. Solomkin JS, Yellin AE, Rotstein OD, et al. Ertapenem versus piperacillin/tazobactam in the treatment of complicated intraabdominal infections: result of a double-blind, randomized, comparative phase III trial. Ann Surg. 2003;237:235-245.

70. Roy S, Higared I, Angel-Muller E, et al. Ertapenem once day versus piperacillin/tazobactam every $6 \mathrm{~h}$ for treatment of acute pelvic infections: a prospective, multicenter, randomized, double blind study. Infect Dis Obstetr Gynaecol. 2003;11:27-37.

71. Ortiz-Ruiz G, Caballero-Lopez J, Friedland IR, Woods GL, Carides A; Protocol 018 Ertapenem Community-Acquired Pneumonia Study Group. A study evaluating the efficacy, safety, and tolerability of ertapenem versus ceftriaxone for the treatment of community-acquired pneumonia in adults. Clin Infect Dis. 2002;34:1076-1083.

72. Graham DR, Lucasti C, Malafaia O, et al. Ertapenem once daily versus piperacillin-tazobactam 4 times per day for treatment of complicated skin and skin-structure infections in adults: results of a prospective, randomized, double-blind multicenter study. Clin Infect Dis. 2002;34: $1460-1468$.

73. Tomera KM, Burdmann EA, Reyna OG, et al; Protocol 014 Study Group. Ertapenem versus ceftriaxone followed by appropriate oral therapy for therapy of complicated urinary tract infections in adults: results of a prospective, randomized, double-blind multicenter study. Antimicrob Agents Chemother. 2003;46:2895-2800.

74. Jimenez-Cruz F, Jasovich A, Cajigas J, et al. A prospective, multicenter, randomized, double-blind study comparing ertapenem and ceftriaxone followed by appropriate oral therapy for complicated urinary tract infections in adults. Urology. 2002;60:16-22.

75. Itani KMF, Wilson SE, Awad SS, Jensen EH, Finn TS, Abramson MA. Ertapenem versus cefotetan prophylaxis in elective colorectal surgery. N Engl J Med. 2006;355:2640-2651.

76. Goldstein EJ, Citron DM, Merriam CV, Abramson MA. Infection after elective colorectal surgery: bacteriological analysis of failures in a randomized trial of cefotetan vs ertapenem prophylaxis. Surg Infect. 2009;10:111-118.

77. Wilson SE, Turpin RS, Kumar RN, et al. Comparative costs of ertapenem and cefotetan as prophylaxis for elective colorectal surgery. Surg Infect. 2008;8:349-356.

78. Hershman MJ, Swift RI, Reilly DT, et al. Prospective, comparative study of cefotetan with piperacillin for prophylaxis against infection in elective colorectal surgery. J R Coll Surg Edinb. 1990;35:29-32.

79. Milsom JW, Smith DL, Corman ML, Howerton RA, Yellin AE, Luke DR. Double-blind comparison of single dose alatrofloxacin and cefotetan as prophylaxis of infection following elective colorectal surgery. Am J Surg. 1998;176(Suppl 6 A):46S-52S.

80. Arnaud JP, Bellissant E, Boissel P, et al. Single-dose amoxycillinclavulanic acid vs cefotetan for prophylaxis in elective colorectal surgery: a multicentre, prospective, randomized study. J Hosp Infect. 1992;22(Suppl A):S23-S32.

81. Bellantone R, Pacelli F, Sofo L, et al. Systemic perioperative prophylaxis in elective oncological colorectal surgery: cefotetan versus clindamicin plus aztreonam. Drugs Exp Clin Res. 1988;14:763-766.

82. Periti P, Mazzei T, Tonelli F. Single-dose cefotetan vs. multiple doses cefoxitin antimicrobial prophylaxis in colorectal surgery: results of a prospective, multicenter, randomized study. Dis Colon Rectum. 1989;32:121-127.

83. Periti P, Tonelli F, Mazzei T, Ficari F. Antimicrobial chemoimmunoprophylaxis in colorectal surgery with cefotetan and thymostimulin: prospective, controlled multicenter study. J Chemother. 1993;5: 37-42.

84. Skipper D, Karran SJ. A randomized prospective study to compare cefotetan with cefuroxime plus metronidazole as prophylaxis in elective colorectal surgery. J Hosp Infect. 1992;21:73-77. 
85. Morton AL, Taylor EW, Lindsay G, Wells GR. A multicenter study to compare cefotetan alone with cefotetan and metronidazole as prophylaxis against infection in elective colorectal operations. Surg Gynecol Obstet. 1989;169:41-45.

86. Jagelman DG, Fabian TC, Nichols RL, Stone HH, Wilson SE, Zellner SR. Single-dose cefotetan versus multiple-dose cefoxitin as prophylaxis in colorectal surgery. Am J Surg. 1988;155:71-76.

87. Itani KM, Jensen EH, Finn TS, Tomassini JE, Abramson MA. Effect of body mass index and ertapenem versus cefotetan prophylaxis on surgical site infection in elective colorectal surgery. Surg Infect. 2008;9:131-137.

88. Martin C, Portet C, Lambert D, et al. Pharmacokinetics and tissue penetration of single-dose cefotetan used for antimicrobial prophylaxis in patients undergoing colorectal surgery. Antimicrob Agents Chemother. 1992;36:1115-1118.

89. Bratzler DW, Hunt DR. The surgical infection prevention and surgical care improvement projects: national initiatives to improve outcomes for patients having surgery. Clin Infect Dis. 2006;43: 322-330.

90. Song F, Glenny AM, Altman DG. Indirect comparison in evaluating efficacy illustrated by antimicrobial prophylaxis in colorectal surgery. Control Clin Trials. 2000;21:488-497.

91. Sexton DJ. Carbapenem for surgical prophylaxis? $N$ Engl J Med. 2006;366:2693-2695.
92. Dinubile MJ, Friedland D, Chan CY, et al. Bowel colonization with resistant gram-negative bacilli after antimicrobial therapy of intra-abdominal infections: observations from two randomized comparative clinical trials of ertapenem therapy. Eur J Clin Microbiol Infect Dis. 2005;24:443-449.

93. Bartlett JG, Chang TW, Gurwith M, Gorbach SI, Onderdonk AB Antibiotic-associated pseudomembranous colitis due to toxin-producing clostridia. N Engl J Med. 1978;298:531-534.

94. Monaghan T, Boswell T, Mahida YR. Recent advances in Clostridium difficile-associated disease. Gut. 2008;57:850-860.

95. Weir E, Flegel K. Protecting against Clostridium difficile illness. CMAJ 2005;172:1178.

96. Kuijper EJ, Coignard B, Tull P, et al. Emergence of Clostridium difficileassociated disease in North America and Europe. Clin Microbiol Infect. 2006;12(Suppl 6):S2-S18.

97. Hubert B, Loo VG, Burgault AM, et al. A portrait of the geographic dissemination of the Clostridium difficile North American pulsed-field type 1 strain and the epidemiology of $C$. difficile-associated disease in Québec. Clin Infect Dis. 2007;44:238-244.

98. Kyne L, Hamel MB, Polavaram R, Kelly CP. Health costs and mortality associated with nosocomial diarrhea due to Clostridium difficile. Clin Infect Dis. 2002;34:346-353.

99. Zerey M, Paton BL, Lincourt AE, Gersin KS, Kercher KW, Heniford BT. The burden of Clostridium difficile in surgical patients in the United States. Surg Infect. 2004;42:1203-1206.
Therapeutics and Clinical Risk Management

\section{Publish your work in this journal}

Therapeutics and Clinical Risk Management is an international, peerreviewed journal of clinical therapeutics and risk management, focusing on concise rapid reporting of clinical studies in all therapeutic areas, outcomes, safety, and programs for the effective, safe, and sustained use of medicines. This journal is indexed on PubMed Central, CAS

\section{Dovepress}

EMBase, Scopus and the Elsevier Bibliographic databases. The manuscript management system is completely online and includes a very quick and fair peer-review system, which is all easy to use. Visit http://www.dovepress.com/testimonials.php to read real quotes from published authors.

Submit your manuscript here: http://www.dovepress.com/therapeutics-and-clinical-risk-management-journal 